\title{
Comparative tadpole morphology in three species of frogs of the genus Spinomantis (Amphibia: Mantellidae)
}

\author{
Silvia Vejarano ${ }^{1}$, Meike Thomas ${ }^{2}$ and Miguel Vences ${ }^{1,3}$ \\ ${ }^{1}$ Institute for Biodiversity and Ecosystem Dynamics, Zoological Museum, University of Amsterdam, Mauritskade \\ 61, 1092 AD, Amsterdam, The Netherlands; ${ }^{2}$ Institute for Genetics, Evolutionary Genetics, University of Co- \\ logne, Weyertal 121, 50931 Cologne, Germany; ${ }^{3}$ Current address: Zoological Institute, Technical University \\ of Braunschweig, Spielmannstr. 8, 38106 Braunschweig, Germany; e-mail: m.vences@tu-bs.de
}

Key words: Anura, Spinomantis aglavei, Spinomantis phantasticus, Spinomantis fimbriatus, Madagascar, systematics, DNA barcoding

\begin{abstract}
We describe the tadpoles of three species of Malagasy frogs, classified in the genus Spinomantis, based on specimens identified by DNA barcoding. The tadpole of Spinomantis aglavei is a typical Orton type IV larva. The oral disc is not emarginated laterally, but has two mid-ventral folds and a labial tooth row formula of 3(23)/2(1). The tadpole of $S$. phantasticus is similar, the oral disc being laterally emarginated and having one medial fold; LTRF is 3/3(1). A third species, S. cf. fimbriatus is also similar to the other two species; the oral disc is not laterally emarginated but has three medial folds and LTRF is 3(2-3)/3(1). One shared character is a median fold or emargination in the lower part of the oral disc, although the shape of this fold is different in each of the three species. Only single specimens were available for examination in S. aglavei and S. phantasticus, preventing a further discussion of intraspecific morphological variation and of possibly diagnostic characters of larval morphology.
\end{abstract}

\section{Contents}

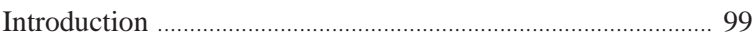

Material and methods ................................................................ 100

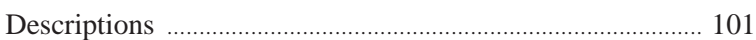

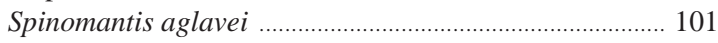

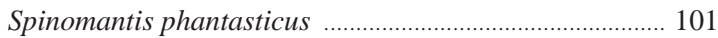

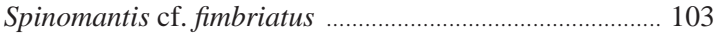

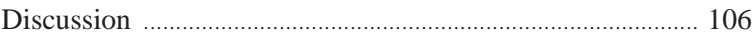

Acknowledgements ................................................................. 107

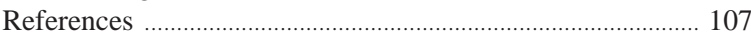

\section{Introduction}

The vertebrate fauna of Madagascar is characterized by an elevated degree of species-level endemism, amounting to $100 \%$ for native amphibians, and con- tains a number of highly diversified endemic radiations (Glaw and Vences, 2003; Vences, 2005). Amphibians in Madagascar are represented by frogs only; salamanders and caecilians are not known. Besides a number of relatively recent colonizers such as hyperoliid frogs and Ptychadena mascareniensis, and several speciespoor putative relict groups such as scaphiophrynine and dyscophine microhylids, the vast majority of Malagasy frogs is made up by two endemic radiations, the family Mantellidae and the microhylid subfamily Cophylinae (Glaw and Vences, 2003).

Whereas Guibé (1978), in his monograph of Malagasy amphibians, included only rudimentary information on their biology and ecology and almost no data on larval stages, the situation quickly improved after the thorough biosystematic studies of Rose Blommers-Schlösser, carried out in the Zoological Museum Amsterdam in the late 1970s after several years of fieldwork in Madagascar (e.g., Blommers-Schlösser, 1979), and summarized by Blommers-Schlösser and Blanc (1991). She also defined species groups for the large mantellid genus Mantidactylus most of which were later (Dubois, 1992; Glaw and Vences, 1994) elevated to subgenus rank. In a recent paper, Glaw and Vences (2006) partitioned the heterogeneous and paraphyletic genus Mantidactylus into seven monophyletic genera according their molecular phylogenetic analysis. The classification proposed by these authors has also been applied in a recent bioacoustic soundguide to Malagasy frogs (Vences et al., 2006) and will be followed herein as well.

From the 1990s on a massive amount of publications have increased the knowledge on Malagasy 
frogs thanks to the work of various scientists determined to untangle the intricate problems with their systematics. A large amount of new species have been described, and many others have already been identified but await formal description (Glaw and Vences, 2000; Köhler et al., 2005). However, while huge progress has been made in describing the adult stages of Malagasy frogs, the tadpoles of many of the 203 currently named and valid mantellid species (Köhler et al., 2005) remain unknown. As typical in hyperdiverse tropical amphibian faunas, numerous rainforest sites in Madagascar harbour large numbers of sympatric frog species, and these are often morphologically similar. Tadpole identification under these conditions was so far very time-intensive as it required the search for mating pairs of well-identified adult frogs, and subsequent rearing of tadpoles from clutches deposited by these specimens. Alternatively, wild-caught tadpoles could be reared through metamorphosis and the juveniles tentatively determined, but due to the large amount of cryptic species this method is very error-prone. As a consequence, many of the tadpoles described by BlommersSchlösser (1979), although certainly correctly attributed to subgenera or species groups, might be incorrectly identified to species. Recent emergence of widely applicable DNA barcoding techniques (Hebert et al., 2003) offer a new perspective to a large-scale identification of divergent life-history stages of organisms (e.g., Hebert et al., 2004), among them tadpoles (Thomas et al., 2005; Vences et al., 2005).

In this paper we apply DNA barcoding-based identification to a group of mantellid frogs considered as the genus Spinomantis Dubois, 1992. This group had originally been designated as the monospecific Mantidactylus aglavei-group by Blommers-Schlösser (1979), and subsequently as subgenus of Mantidactylus, but currently is seen as separate genus containing nine species (Vences and Glaw, 2005; Glaw and Vences, 2006): Spinomantis aglavei, S. bertini, S. brunae, S. elegans, S. guibei, S. fimbriatus, S. massorum, S. microtis, S. phantasticus, S. peraccae.

The only available descriptions of tadpoles of Spinomantis are those of S. aglavei (BlommersSchlösser, 1979) and S. elegans (Thomas et al., 2005). We here complement these data by describing the tadpoles of S. phantasticus and of S. cf. fimbriatus, and we redescribe the tadpole of $S$. aglavei, based on specimens identified by DNA sequences.

\section{Material and methods}

Tadpoles were collected in the field, euthanised by immersion in chlorobutanol solution, and immediately sorted into homogeneous series based on morphological characters. From each series one specimen was selected and a tissue sample from its tail musculature or fin taken and preserved in 99\% ethanol. This specimen is here named 'DNA voucher'. After tissue collection, all specimens were preserved in $4 \%$ formalin. Specimens were deposited in the Zoologische Staatssammlung München, Germany (ZSM); comparative specimens were examined from the herpetological collection of the Zoological Museum Amsterdam, Netherlands (ZMA).

Tadpoles were identified using a DNA barcoding approach based on a fragment of the mitochondrial 16S rRNA gene, which is known to be sufficiently variable among species of Malagasy frogs (Thomas et al., 2005). The 550 bp fragment was amplified using primers 16Sa-L and 16Sb-H from Palumbi et al. (1991) applying standard protocols, resolved on automated sequencers, and compared to a near-complete database of sequences of adult Malagasy frog species. Identification was considered to be unequivocal when the tadpole sequence was $99-100 \%$ identical to an adult specimen from the same geographical region, and not more similar to any sequence from another species. DNA sequences were deposited in Genbank (accession numbers DQ060232DQ060237; accession numbers of comparative adult specimens are included in the sequence set AY847959AY848683).

Drawings and descriptions of the tadpoles in this paper are based only on the DNA vouchers. All specimens of each series were examined to assess morphological variability and to complete the structures missing because of tissue sampling in the DNA vouchers. Developmental stages are based on Gosner (1960). The labial tooth row formula (LTRF) and the morphological descriptions in general follow Altig and McDiarmid (1999). Labial tooth row fomula is in addition also given according to the notation of Dubois (1995). The measurements taken using a stereomicroscope with measuring 
device and converted later into millimetres are: BL = body length (from the tip of the snout to the junction of the posterior body wall with the axis of the tail myotomes); BW = body width (the widest point of the 'head' right behind the eyes); ED = eye diameter; IOD = interorbital distance (from the centre of each pupil); $\mathrm{TH}=$ tail height (at the beginning of the tail); TMW = tail muscle width (at the beginning of the tail); MTH = tail height at mid-length of tail (including caudal fin); TMH = tail muscle height (at mid-length of tail); TAL = tail length; ODW = maximum oral disc width; DGMP = dorsal gap of the marginal papillae. The mouth parts include: MP = number of marginal and SMP = submarginal papillae; LMP = length of the marginal papillae; UTR = upper tooth row; LTR = lower tooth row; NT = number of teeth; LLTR = length of the tooth row.

\section{Descriptions}

Spinomantis aglavei (Methuen and Hewitt, 1913)

Based on ZSM 431/2004 (field number 2002.1817; DQ060232), a single specimen (DNA voucher) in stage 28 (Figs. 1A and 1B) from Kidoanafo bridge, Vohiparara, Ranomafana National park in southeastern Madagascar, collected in a small and muddy brook (211․ ${ }^{\circ} 0^{\prime} \mathrm{S} 47^{\circ} 22.21^{\prime} \mathrm{E}, 846 \mathrm{~m}$ above sea level) in the forest, with many pools but also rapids, diameter between 50 and $100 \mathrm{~cm}$, on 21 January 2003.

For morphometric data see Tables 1 and 2. Coloration in preservative light brown darkening softly towards mid-dorsal body. Four small lines across the middle line of the dorsum. Few small darker spots on the body and intestinal wall. Intestinal spiral visible, densely and regularly rolled. Ventral part of the body lacks pigmentation. Tail (first half) with more or less the same coloration pattern as the body, except the mid lines. The end and a ventral portion of the tail and caudal fin missing because of tissue sampling. Tadpole of type IV (Orton, 1953). Body shape oval. Tail musculature strongly developed. Snout in dorsal view almost rounded. Eyes medium-sized (about 0.1 of body length) dorsally positioned. Nares rounded, positioned closer to snout tip than to center of eye, directed anterolaterally, with their openings directed laterally. Spiracle sinistral, quite anteriorly on body. Oral disc without emarginations but strongly folded mid-ventrally twice (Fig. 1C) and bordered almost entirely with papillae; 54 marginal papillae, those of the ventral part (ca. 25) twice as long and narrower at the base than the lateral ones; dorsal gap of the marginal papillae large $(1.5 \mathrm{~mm})$ about half of oral disc width; two submarginal papillae on each side of the upper lip and nine (short and pointed) on the lower lip, right below LTR $_{2}$. LTRF 1:2+2/1+1:1 (Dubois, 1995) or 3(2-3)/2(1) (Altig and McDiarmid, 1999); UTR 1 and $\mathrm{UTR}_{2}$ subequal in length, $\mathrm{UTR}_{3}$ much shorter; $\mathrm{LTR}_{2}$ shorter than $\mathrm{LTR}_{1}$; UTR $_{3}$ with more teeth per 0.1 millimeter (seven) than the rest of tooth rows (five). $\mathrm{UTR}_{2}$ with a small gap while $\mathrm{UTR}_{3}$ and $\mathrm{LTR}_{1}$ are separated by the jaw sheaths. Jaw sheaths distinct, with a light brown pigmentation and softly serrated edges (ca. 49 in each jaw). Sheath of upper jaw straight and sheath of lower jaw strongly curved in the middle, resembling a wide $\mathrm{V}$.

\section{Spinomantis phantasticus Glaw and Vences, 1997}

Based on ZSM 421/2004 (field number 2002.1637; DQ060233), a single specimen (DNA voucher) in stage 25 (Figs. 2A and 2B) from Andasibe, centraleastern Madagascar, collected on 25 February 2003. Tadpoles were found in a little brook along the railway (1855.14'S 48²6.24'E, $906 \mathrm{~m}$ above sea level), maximum width $1 \mathrm{~m}$, with pools and rapids, and a lot of dead leaves on the bottom. For morphometric data see Tables 1 and 2. Preserved coloration light brown, with a few spots on the snout. Body dorsally with a darker longitudinal stripe and several transverse, shorter stripes. Almost no coloration on the intestinal wall; ventral part of the body lacking pigmentation; tail also with dorsal transverse stripes in the first part, and the rest of the tail with short stripes on the sides. The distal portion of the tail and caudal fin missing because of tissue sampling. Tadpole of type IV (Orton, 1953). Body shape oval. Tail musculature strongly developed. Intestine in a densely and regularly rolled spiral. Snout in dorsal view almost rounded. Eyes medium-sized (about 0.1 of body length) dorsally positioned. Nares rounded, positioned closer to snout tip than to center of eye, directed anterolaterally, with their openings directed laterally. Spiracle sinistral, quite anteriorly on body. Oral disc laterally emarginated with one medial fold in the lower part and bordered by ca. 106 marginal 


\section{a}

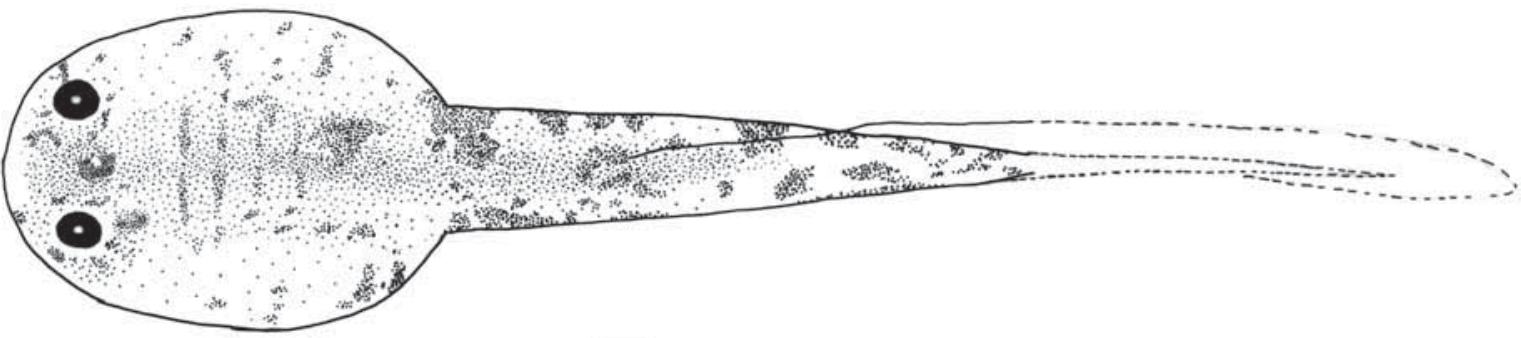

$2 \mathrm{~mm}$

b
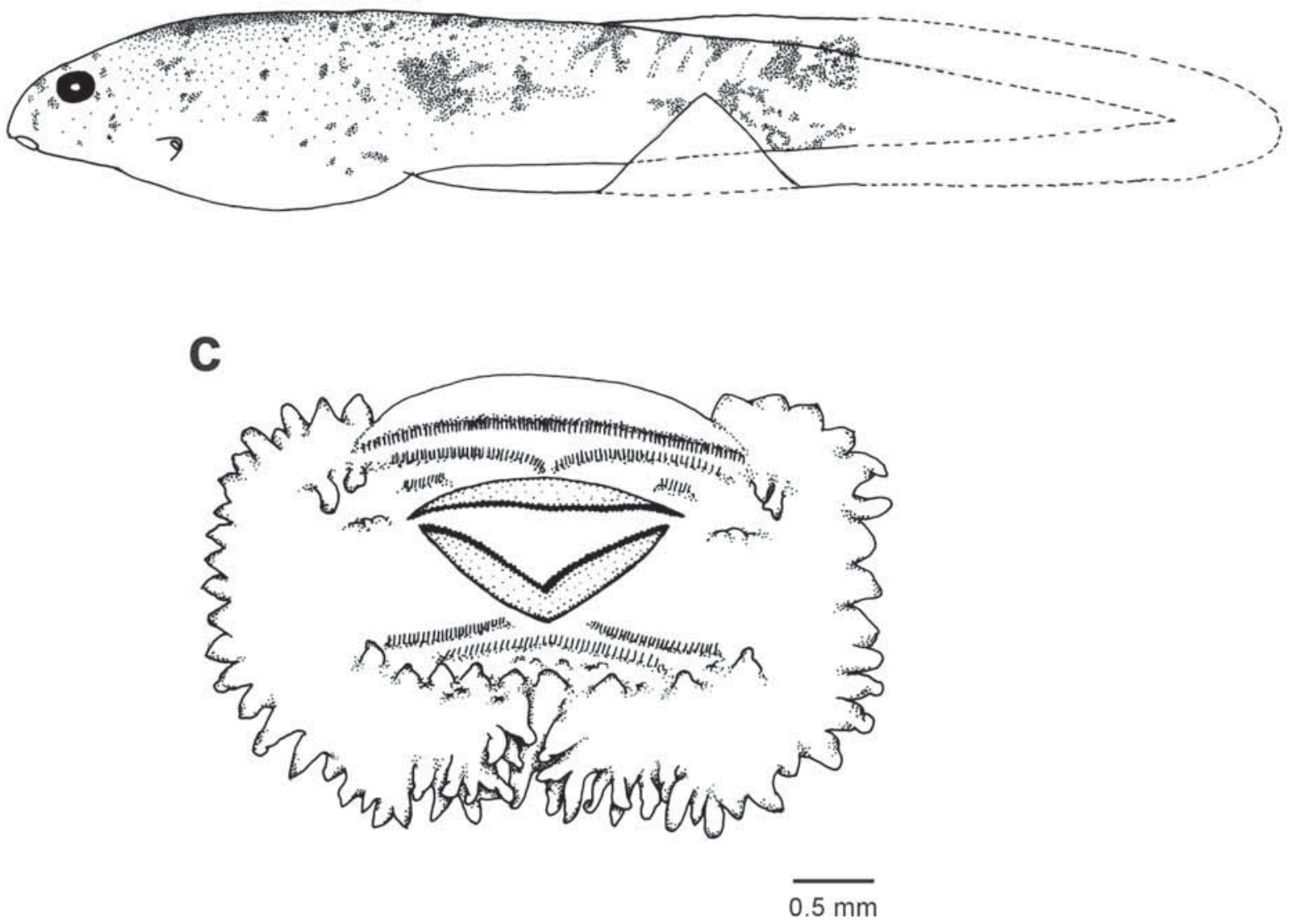

Fig. 1. Drawings of the preserved DNA voucher tadpole of Spinomantis aglavei. Series ZSM 431/2004; (A) Dorsal view. (B) Lateral view. (C) Oral disc.

papillae (Fig. 2C); dorsal gap of the marginal papillae short $(1.25 \mathrm{~mm})$ about 0.3 of oral disc width. Marginal papillae of the anterior part of the lip are more separated and slightly shorter than the ventral ones $(0.13 \mathrm{~mm})$; ventral papillae which are closer to the emargination are few and small, and increase in length and number as they reach the centre $(0.23$ $\mathrm{mm}$ ); seven submarginal papillae below the $\mathrm{LTR}_{3}$. LTRF 3/1+1:2 (Dubois, 1995) or 3/3(1) (Altig and McDiarmid, 1999); all three UTR without very important length differences, UTR 1 slightly shorter than $\mathrm{UTR}_{2}$ and $\mathrm{UTR}_{3}$; $\mathrm{LTR}_{2}$ shorter than $\mathrm{LTR}_{1}, \mathrm{LTR}_{3}$ 
Table 1. Morphometric measurements (all in mm) of the DNA vouchers of all species. DNA vouchers used for descriptions and drawings are marked with asterisks.

\begin{tabular}{|c|c|c|c|c|c|c|}
\hline & S. aglavei & S. phantasticus & S. cf. fimbriatus & S. cf. fimbriatus & S. cf. fimbriatus & S. cf. fimbriatus \\
\hline & ${ }^{*}$ ZSM 431/2004 & ${ }^{*}$ ZSM 421/2004 & ${ }^{*}$ ZSM 441/2004 & ZSM 443/2004 & ZSM 445/2004 & ZSM 417/2004 \\
\hline Stage & 28 & 25 & 28 & 26 & 25 & 25 \\
\hline $\mathrm{BL}$ & 15.47 & 16.09 & 16.41 & 13.59 & 10.31 & 8.59 \\
\hline BW & 8.28 & 10.16 & 8.44 & 7.81 & 5.94 & 4.53 \\
\hline ODW & 3.06 & 3.81 & 3.44 & 2.78 & 2.45 & 1.73 \\
\hline DGMP & 1.50 & 1.25 & 0.94 & 1.15 & 0.83 & 0.73 \\
\hline IOD & 4.69 & 5.19 & 4.69 & 3.91 & 2.18 & 2.19 \\
\hline ED & 1.56 & 1.56 & 1.41 & 1.09 & 0.94 & 0.63 \\
\hline $\mathrm{TH}$ & 5.47 & 6.25 & 5.16 & 4.84 & 3.44 & 2.50 \\
\hline TMW & 4.69 & 4.84 & 5.00 & 4.06 & 3.13 & 2.19 \\
\hline MTH & - & - & 6.88 & - & - & - \\
\hline TMH & - & 5.94 & 4.06 & - & - & - \\
\hline TAL & - & - & 32.03 & - & - & - \\
\hline LMP & $0.08-0.13$ & $0.13-0.23$ & 0.1 & $0.05-0.1$ & - & - \\
\hline $\mathrm{UTR}_{1}$ & 1.55 & 1.35 & 0.63 & 1.08 & 0.60 & 0.73 \\
\hline $\mathrm{UTR}_{2}$ & 0.70 & 1.93 & 0.75 & 0.65 & 1.03 & 0.35 \\
\hline $\mathrm{UTR}_{3}$ & 0.13 & 0.95 & 0.15 & 0.13 & 0.15 & \\
\hline $\mathrm{LTR}_{1}$ & 0.63 & 0.83 & 0.70 & 0.55 & 0.68 & 0.35 \\
\hline $\mathrm{LTR}_{2}$ & 0.80 & 1.45 & 0.90 & 0.63 & 0.48 & 0.28 \\
\hline $\mathrm{LTR}_{3}$ & - & 1.25 & 0.15 & 0.13 & - & - \\
\hline
\end{tabular}

Table 2. Number of marginal and submarginal papillae (MP, SMP) and number of teeth per labial tooth row of DNA voucher specimens examined. For rows divided by a gap, the number of teeth presented on the table is the average of the numbers on each side of the tooth row. DNA vouchers used for descriptions and drawings are marked with asterisks. LTRF: ${ }^{1}$ after Dubois (1995); ${ }^{2}$ after Altig and McDiarmid (1999).

\begin{tabular}{|c|c|c|c|c|c|c|}
\hline & S. aglavei & S. phantasticus & S. cf. fimbriatus & S. cf. fimbriatus & S. cf. fimbriatus & S. cf. fimbriatus \\
\hline & *ZSM 431/2004 & *ZSM 421/2004 & *ZSM 441/2004 & ZSM 443/2004 & ZSM 445/2004 & ZSM 417/2004 \\
\hline$\overline{\mathrm{MP}}$ & 54 & 106 & 85 & 73 & 83 & 48 \\
\hline SMP & 11 & 7 & 26 & 17 & 0 & 0 \\
\hline $\mathrm{UTR}_{1}$ & 84 & 30 & 23 & 25 & 33 & 31 \\
\hline $\mathrm{UTR}_{2}$ & 34 & 41 & 25 & 17 & 26 & 14 \\
\hline $\mathrm{UTR}_{3}$ & 9 & 51 & 6 & 5 & 7 & - \\
\hline $\mathrm{LTR}_{1}$ & 28 & 20 & 26 & 22 & 27 & 14 \\
\hline $\mathrm{LTR}_{2}$ & 36 & 41 & 37 & 29 & 15 & 12 \\
\hline $\mathrm{LTR}_{3}$ & - & 22 & 8 & 5 & - & - \\
\hline LTRF $^{1}$ & $1: 2+2 / 1+1: 1$ & $3 / 3+3$ & $1: 2+2 / 1+1: 2$ & $1: 2+2 / 1+1: 2$ & $3+3 / 1+1: 1$ & $2+2 / 1+1: 1$ \\
\hline LTRF $^{2}$ & $3(2-3) / 2(1)$ & $3 / 3(1-3)$ & $3(2-3) / 3(1)$ & $3(2-3) / 3(1)$ & $3(1-3) / 2(1)$ & $2(1-2) / 2(1)$ \\
\hline
\end{tabular}

much shorter; $\mathrm{LTR}_{1}$ separated by the lower jaw sheath; $\mathrm{LTR}_{2}$ and $\mathrm{LTR}_{3}$ appear to be separated by two gaps each, but the tooth ridges are in both cases continuous, therefore possibly teeth are missing because of fixation or preservation; maybe for the same reason $\mathrm{LTR}_{3}$ has fewer teeth per millimetre (ca. 17) than the rest of teeth rows (21-28). Around 13 buccopharyngeal papillae; jaw sheaths distinct and dark with serrated edges (ca. 56 in each jaw). Both jaws almost straight, lower jaw only gently curved.

\section{Spinomantis cf. fimbriatus}

Material. ZSM 441/2004 (field number 2002.1843; DQ060234), a single specimen (DNA voucher) collected on 19 January 2003 in a small inflow to a brook locally named Mariavarata (21ํㄷ.78'S $47^{\circ} 25.16^{\prime} \mathrm{E}, 844 \mathrm{~m}$ above sea level), width 50 to $70 \mathrm{~cm}$, a lot of pools with steep regions inbetween. ZSM 443/2004 (field number 2002.1848; DQ060235), series of four specimens collected on 18 January 2003 in an awashed meadow in a clearance locally named 'Sahar'i Bernard' (Bernard's field) in the forest, and ZSM 445/2004 (field number 2002.1873; DQ060236), a single specimen (DNA voucher) collected in a second inflow more downstream of Mariavarata brook, very 

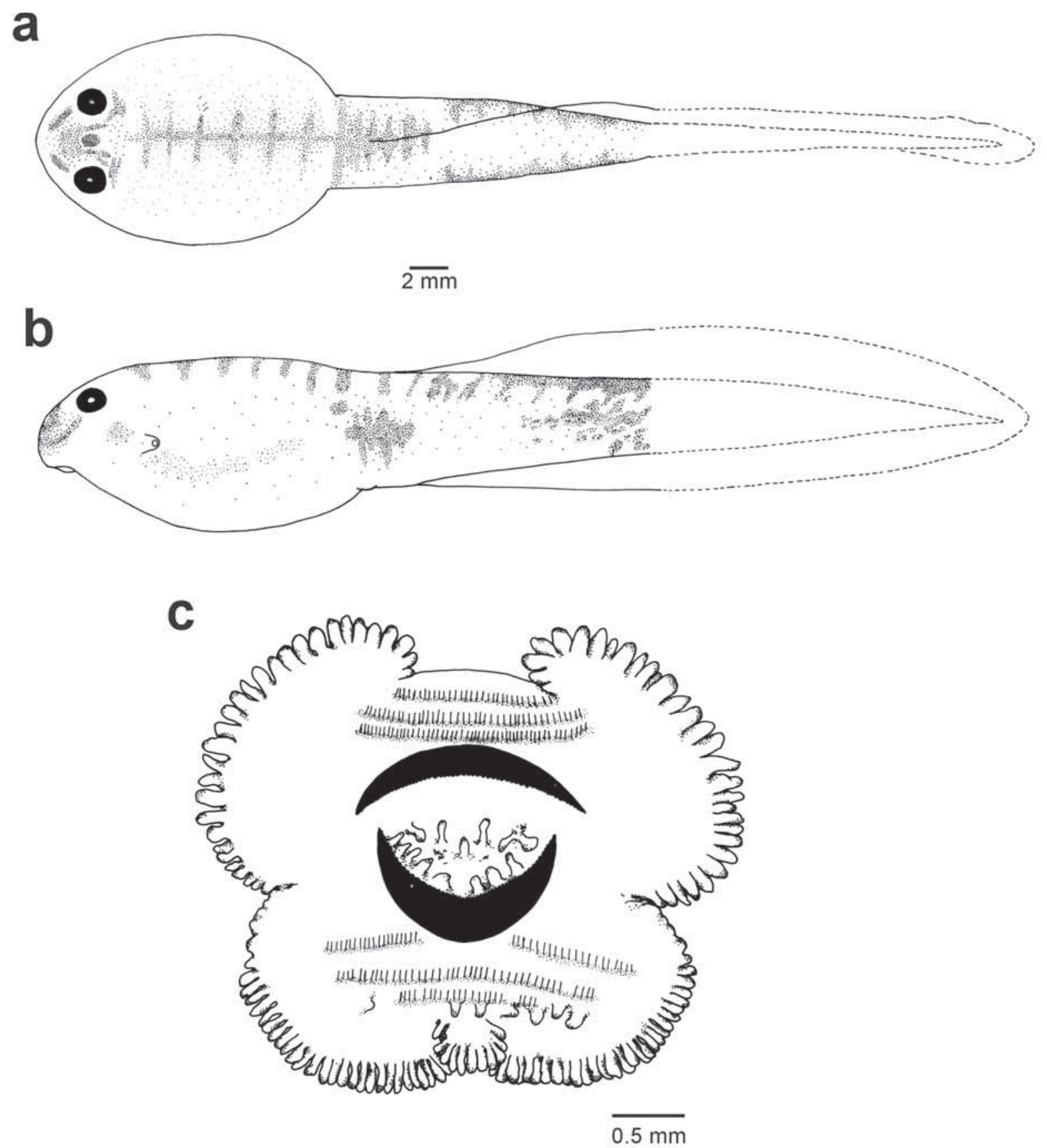

Fig. 2. Drawings of the preserved DNA voucher tadpole of Spinomantis phantasticus. Series ZSM421/2004. (A) Dorsal view. (B) Lateral view. (C) Oral disc

broad (1-4 m) but shallow with a stony bottom and mostly fast flowing water. This tadpole was found in the stream, in a conglomeration of dead leaves on 17 January 2003. All these localities are within the Ranomafana National Park in southeastern Madagascar. ZSM 417/2004 (field number 2002.1631; DQ060237), a single specimen (DNA voucher) from Andasibe, central-eastern Madagascar, collected in a little brook along the

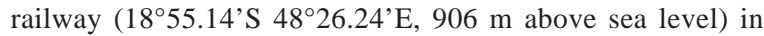
2002. For morphometric data of all DNA voucher specimens, see tables 1 and 2 .

Description (based on the DNA voucher of series ZSM 441/2004). Tadpole in stage 28 (Figs. 3A and 
a
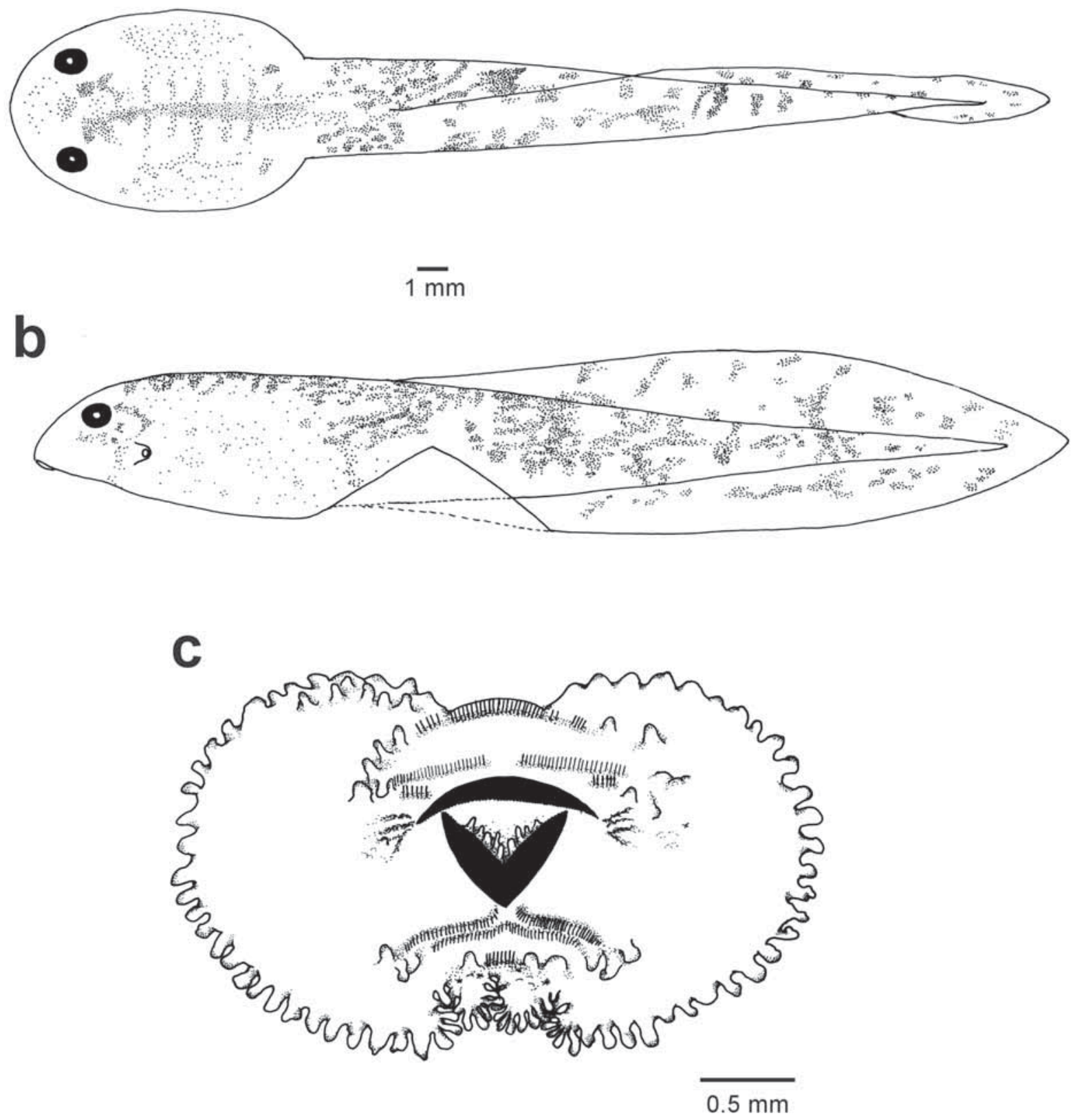

Fig. 3. Drawings of the preserved DNA voucher tadpole of Spinomantis cf. fimbriatus. Series ZSM 441/2004. (A) Dorsal view. (B) Lateral view. (C) Oral disc.

3B). Preserved coloration light brown; few small spots between the eyes; one medial longitudinal stripe and five small transversal stripes on dorsum; intestinal wall almost lacking pigmentation and intestinal spiral visible; tail and caudal fin with many small brown spots. Ventral portion of the tail and caudal fin missing because of tissue sampling. Tadpole of type IV (Orton, 1953). Body shape oval. Tail musculature strongly developed. Tail length $32.9 \mathrm{~mm}$, tail making up two thirds of total length. Intestine in a densely and regularly rolled spiral. Snout in dorsal view almost rounded. Eyes medium-sized (about 0.08 
of body length) dorsally positioned. Nares rounded, positioned closer to snout tip than to center of eye, directed anterolaterally, with their openings directed laterally. Spiracle sinistral, quite anteriorly on body. Oral disc with three small ventral emarginations that create two flaps and bordered by papillae (Fig. 3C); 85 marginal papillae, small $(0.1 \mathrm{~mm})$ and rounded; those between the emarginations appear to be thinner than the rest. Dorsal gap of the marginal papillae short $(0.94 \mathrm{~mm})$ about 0.25 of oral disc width; one row of six submarginal papillae on the border of the right (in ventral view) upper part of the oral disc, 11 submarginal papillae around the UTRs and nine around the LTRs. LTRF 1:2+2/1+1:2 (Dubois, 1995) or 3(23)/3(1) (Altig and McDiarmid, 1999); UTR shorter than $\mathrm{UTR}_{2}, \mathrm{UTR}_{3}$ much shorter than $\mathrm{UTR}_{1}$ and $\mathrm{UTR}_{2}$; $\mathrm{LTR}_{2}$ distinctly shorter than $\mathrm{LTR}_{1}$; UTR 1 and $\mathrm{UTR}_{2}$ with less teeth per 0.1 millimetre (36 and 33 respectively) than the rest (38-53) but apparently some teeth are missing because of fixation or preservation; $\mathrm{UTR}_{2}$ separated by a gap and $\mathrm{UTR}_{3}$ separated by the upper jaw sheath. LTR $_{3}$ very short. About 13 buccopharyngeal papillae. Jaw sheaths distinct and black, with softly serrated edges (ca. 72 in each jaw). Sheath of upper jaw straight and sheath of lower jaw strongly curved in the middle, resembling a wide V.

Variation within series. The series ZSM 443/2004 contains four tadpoles, three in stage 26 and one in stage 25. The right portion of the oral disc of tadpole in stage 25 is poorly preserved and therefore the LTRF [1:2+2/1+1:1 (Dubois, 1995) or 3(2-3)/2(1) (Altig and McDiarmid, 1999)], number of marginal and submarginal papillae recorded is not reliable. A further specimen has the $\mathrm{LTR}_{3}$ divided in two portions with five labial teeth on each side. The other two tadpoles have LTRF 1:2+2/1+1:2 (Dubois, 1995) or 3(2-3)/3(1) (Altig and McDiarmid, 1999). Number of marginal papillae is not highly variable 66-73. The submarginal papillae have similar number and arrangement. Coloration varies from one specimen with darker, more uniform coloration to another specimen with also uniform but much lighter coloration. All other tadpoles agree in general and oral morphology with the DNA voucher as shown in Fig. 3.

Variation among the series (Table 2). The series ZSM $445 / 2004$ and 417/2004 contain only the DNA voucher specimen each, both in stage 25 . The tadpole from series ZSM 417/2004 has a LTRF of 2+2/1+1:1 (Dubois, 1995) or 2(2)/2(1) (Altig and McDiarmid, 1999), few marginal papillae (48), and in general is smaller $(\mathrm{BL}=8.6 \mathrm{~mm})$ than the DNA voucher specimens of other series (mean $B L=13.44 \pm 3.05 \mathrm{~mm}$ ) and from all other examined specimens (mean $\mathrm{BL}=13.72 \pm 2.09 \mathrm{~mm}$ ). Coloration is also different, very light with almost no pigmentation at all.

The tadpole from series ZSM 445/2004 appears to have only the $\mathrm{UTR}_{3}$ divided, but the $\mathrm{UTR}_{2}$ spite the gap is not clearly visible, has two separate tooth ridges. Both tadpoles differ from the DNA voucher in not having submarginal papillae. In every other respect this and the DNA voucher of series ZSM 443/2004 agree with the specimen as shown in Fig. 3.

Remark. The DNA sequences of these tadpoles were highly divergent from Spinomantis aglavei. The one sequence from Andasibe also was distinctly divergent from the three Ranomafana sequences that were identical among each other. Most probably, these tadpoles are to be assigned to Spinomantis fimbriatus Glaw and Vences, 1994 which is known to occur in the Andasibe region (Glaw and Vences, 1994), and is so far the only Spinomantis not included in our reference data base of DNA sequences. Because so far no DNA sequence of adults of this species from either Ranomafana or Andasibe are available, and the final identification of these larvae awaits further collection of adult material.

\section{Discussion}

According to a previous description (BlommersSchlösser, 1979), the tadpoles of Spinomantis aglavei are characterized by a rounded margin of the oral disc, a small dorsal gap of the marginal papillae and a labial tooth row formula of 3(3)/2(1) or 2/2(1). This oral morphology is unusual in other mantellid frogs where most of the species that have tooth rows present a medial gap from the second upper tooth row on, much larger than in tadpoles of Spinomantis as described by Blommers-Schlösser (1979) for a presumed tadpole of S. aglavei, and herein for three species. The tadpole of $S$. aglavei examined here differs from the previous description of this species (Blommers-Schlösser, 1979) by the presence of a median fold in the lower part of the oral disc and in 
a larger dorsal gap of the marginal papillae $(1.5 \mathrm{~mm})$. Actually the ratio oral disc width to dorsal gap is 2.04, the smallest among the three species studied (3.05 in M. phantasticus and 3.66 in M. cf. fimbriatus). However, in other characters, especially in the presence of only two lower tooth rows which is unique among Malagasy frogs (Blommers-Schlösser and Blanc, 1991; Glaw and Vences, 1994) our data agree with the published information, making it likely that the specimens studied by BlommersSchlösser (1979) had been correctly identified.

The tadpole of $S$. phantasticus has an emarginated oral disc and more marginal papillae (106) than the others (54 in S. aglavei and 85 in S. cf. fimbriatus). The tadpole of $S$. aglavei has a higher number of labial teeth per millimetre in all tooth rows except the third as compared to the other species: 44-54 teeth/mm vs. 21-28 in S. phantasticus and 33-41 in $S$. cf. fimbriatus. One character shared by the three species is a median fold or emargination in the lower part of the oral disc, although the shape of this fold is different in all of them. However, since only one specimen of $S$. phantasticus and S. aglavei were examined for this description, the characters here presented might turn out to show intraspecific variability when further material becomes available.

One of the characters attributed to the tadpoles of the subgenus Spinomantis is the tooth formula with only two lower tooth rows (Blommers-Schlösser, 1979; Glaw and Vences, 1994). Our results confirm this tooth row pattern for $S$. aglavei, but the tadpoles of $S$. phantasticus and M. cf. fimbriatus both have three lower tooth rows. Also another species attributed to Spinomantis by molecular data (Vences and Glaw, 2005), the montane frog Spinomantis elegans has a tooth row formula with three lower tooth rows. Furthermore, tadpoles of this latter species get very large, have a distinct dark coloration, characteristic of high altitude tadpoles, and six or seven upper tooth rows, their oral disc therefore resembling that of Guibemantis depressiceps or G. kathrinae (Thomas et al., 2005). Although all Spinomantis tadpoles known so far live in lotic environments, they apparently evolved a number of quite distinct larval morphologies that might represent different trophic or microhabitat specializations.

Our descriptions include the tadpoles of one species of which the identity is not yet fully clarified and which is therefore here named Spinomantis cf. fim- briatus. Despite numerous attempts every year since 2000, we have been unable to capture adult S. fimbriatus from their type locality Andasibe, and DNA sequences of specimens from northern Madagascar collected by F. Andreone and morphologically close to $S$. fimbriatus differ distinctly from the sequences of the tadpole specimens studied here (M. Vences, pers. obs.). On the other hand, our genetic sampling includes all other described species of Spinomantis, and the tadpole sequences do not match any of those. We therefore are confident that our tadpoles do indeed represent $S$. fimbriatus, and that specimens assigned to that species from northern Madagascar may be attributable to a distinct, undescribed taxon. However uncertain this identification may be, the example illustrates the power of molecular identification of life history stages in comparison to traditional methods (see Hebert et al., 2004): the fact that DNA sequences of a standard gene fragment, easy to amplify and sequence, are deposited in a publically available database (under Genbank accession numbers DQ060234- DQ060237) and are available for these tadpoles makes a corroboration or rejection of their attribution to $S$. fimbriatus unequivocally possible as soon as tissues of well-identified adults of this species become available for molecular comparison. If the tadpoles do not belong to S. fimbriatus they must belong to a new, undescribed species, and could be attributed to that species after adult specimens are collected, studied genetically, and described.

\section{Acknowledgements}

We are indebted to the Malagasy authorities for research and export permits, and to several friends and colleagues for assistance in the field: Frank Glaw, Marta Puente, Liliane Raharivololoniaina, RogerDaniel Dandrianiaina, and David R. Vieites. We acknowledge financial support from the Volkswagen Foundation.

\section{References}

Altig R, McDiarmid RW. 1999. Body plan. Development and morphology. In: McDiarmid RW, Altig R, eds. Tadpoles: the biology of anuran larvae. Chicago Univ. Press, 24-51.

Blommers-Schlösser RMA. 1979. Biosystematics of Malagasy frogs. I. Mantellinae (Ranidae). Beaufortia. 29 (352): 1-77. 
Blommers-Schlösser RMA, Blanc CP. 1991. Amphibiens (première partie). Faune de Madagascar 75 (1): 1-379.

Dubois A. 1992. Notes sur la classification des Ranidae (Amphibiens, Anoures). Bull. Soc. Linn. Lyon. 61: 305-352.

Dubois A. 1995. Keratodont formulae in anuran tadpoles: proposals for a standardization. J. Zool. Syst. Evol. Res. 33: i-Xv.

Glaw F, Vences M. 1994. A fieldguide to the amphibians and reptiles of Madagascar ( $2^{\text {nd }}$ edition). Vences and Glaw Verlag, Köln.

Glaw F, Vences M. 2000. Current counts of species diversity and endemism of Malagasy amphibians and reptiles. In: Lourenço WR, Goodman SM eds. Diversité et endemisme de Madagascar. Mém. Soc. Biogéog. Paris, 243-248.

Glaw F, Vences M. 2003. Introduction to amphibians. In: Goodman SM, Benstead JP, eds. The natural history of Madagascar. Chicago Univ. Press, Chicago and London, 883-898.

Glaw F, Vences M. 2006. Phylogeny and genus-level classification of mantellid frogs. Org. Divers. Evol., 6: 236-253.

Gosner KL. 1960. A simplified table for staging anuran embryos and larvae with notes on identification. Herpetologica. 16: 183-190.

Guibé J. 1978. Les batraciens de Madagascar. Bonn. Zool. Monogr. 11: 1-140.

Hebert PDN, Cywinska A, Ball SL, Dewaard JR. 2003. Biological identification through DNA barcodes. Proc. R. Soc. Lond. Ser. B. 270: 313-321.

Hebert PDN, Enton EH, Burns JM, Janzen DH, Hallwachs W. 2004. Ten species in one: DNA barcoding reveals cryptic species in the Neotropical skipper butterfly Astraptes fulgerator. Proc. Natl. Acad. Sci. USA 101: 14812-14817.
Köhler J, Vieites DR, Bonett RM, Hita García F, Glaw F, Steinke D, Vences M. 2005. New amphibians and global conservation: A boost in species discoveries in a highly endangered vertebrate group. Bioscience. 55 (8): 693-696.

Orton GL. 1953. The systematics of vertebrate larvae. Syst. Zool. 2: $63-75$.

Palumbi SR, Martin A, Romano S, McMillan WO, Stice I, Grabowski G. 1991. The simple fool's guide to PCR, version 2.0., Privately published. Univ. Hawaii.

Thomas M, Raharivololoniaina I, Glaw F, Vences M, Vieites DR. 2005. Montane tadpoles in Madagascar: molecular identification and description of the larval stages of Mantidactylus elegans, M. madecassus and Boophis laurenti from the Andringitra massif. Copeia 2005: 174-183.

Vences M. 2005. Madagascar as a model region for the study of tempo and pattern in adaptive radiations. In: Huber B, Sinclair BJ, Lampe KH, eds. African biodiversity - molecules, organisms, ecosystems. Springer, 69-84.

Vences M, Glaw F. 2005. A new species of Mantidactylus from the east coast of Madagascar and its molecular phylogenetic relationships within the subgenus Guibemantis. Herpetol. J. 15: 37-44.

Vences M, Glaw F, Marquez R. 2006. The calls of the frogs of Madagascar. 3 Audio CD’s and booklet, 44 pp. Alosa, Barcelona.

Vences M, Thomas M, Meijden A van der, Chiari I, Vieites DR. 2005. Comparative performance of the 16s rRNA gene in DNA barcoding of amphibians. Front. Zool. 2, 5.

Received: 8 September 2005

Accepted: 25 May 2006 